\title{
25 Research Square \\ Cervical Spine Clearance on Trauma Intensive Care: Can We Trust a Negative CT Scan?
}

\author{
Abdalla K H Hasandarras \\ Hamad Medical Corporation \\ Gustav F Strandvik ( $\nabla$ gstrandvik@hamad.qa ) \\ Hamad Medical Corporation \\ Ahmed El Faramawy \\ Hamad Medical Corporation \\ Noreddin Nasereldin Areibi \\ Hamad Medical Corporation \\ Basil Younis \\ Hamad Medical Corporation \\ Ahammed Mekkodothil \\ Hamad Medical Corporation \\ Ayman El-Menyer \\ Hamad Medical Corporation \\ Sandro Rizoli \\ Hamad Medical Corporation \\ Hassan Al-Thani \\ Hamad Medical Corporation
}

\section{Research Article}

Keywords: Cervical Spine Clearance, Trauma Intensive Care, Negative, CT Scan, cervical collar, computerized tomography, X-Radiography

Posted Date: July 19th, 2021

DOl: https://doi.org/10.21203/rs.3.rs-698509/v1

License: (c) (i) This work is licensed under a Creative Commons Attribution 4.0 International License. Read Full License 


\section{Abstract}

Background: Cervical spine clearance in intubated victims of blunt trauma remains contentious; accumulating high level evidence suggests that a normal CT cervical spine can be used to clear the c-spine and remove the collar in obtunded emergency department patients to prevent collar-related complications. However, it is unclear whether this holds true for intubated patients in the trauma intensive care unit (TICU).

Methods: We performed a retrospective review of 730 intubated trauma patients who presented to the Level 1 Trauma center of a tertiary hospital. We reviewed the rate of missed cervical injuries in patients who had their cervical collars removed based on a normal computed tomography (CT) scan of the cervical spine, as well as rates of collar-related complications.

Results: Three hundred and fifty patients had their cervical collars removed in the TICU based on the findings of a high-quality, well-interpreted normal CT cervical spine. Seventy percent of patients were intubated and sedated at the time of collar removal. Fifty-one percent of patients had concomitant traumatic brain injury. The average GCS at time of collar removal was 9 . The incidence of missed neurological injury discerned clinically at time of both ICU and hospital discharge was nil (negative predictive value $100 \%$ ). The rate of collar-related complications was $2 \%$.

Conclusion: Based on our findings, it is safe to remove the cervical collar for patients in the TICU following normal CT cervical spine, provided certain quality conditions related to the CT scan are met. Not removing the collar early may be related to increased complications. We provide an algorithm to assist critical-care clinicians in decisionmaking in this patient cohort

\section{Introduction}

Semi-rigid cervical collars (henceforth referred to as 'cervical collars') are routinely applied pre-hospital to many injured patients who have sustained a significant mechanism of injury. The earliest patent listed for a cervical collar (CC) is Circa 1945 in the United States of America (1). It is thought that cervical collars have been used regularly in pre-hospital care since 1967 (2).

The proposed benefits of $\mathrm{CC}$ are related to immobilization of the potentially fractured cervical spine; until very recently, the application of a $\mathrm{CC}$ has been a standard of care according to the internationally recognized Advanced Trauma Life Support Course (3).

However, there is an ever-growing body of literature suggesting that cervical collars may cause more harm than good (3), as they increase aspiration risk (4), make airway management more difficult (5), increase intra-cranial pressure (ICP) by reducing venous return (6), and can result in pressure ulcers and necrosis (7).

Removing an unnecessary cervical collar at the earliest opportunity is thus seen as an important patient safety goal. Many validated algorithms exist for the clearance of the cervical spine (C-spine) after blunt trauma in conscious alert patients, to allow for the removal of the cervical collar. The most widely used systems include the Canadian Cspine rules and the NEXUS criteria (8). Both systems rely on patients being alert and awake with no significant distracting injuries.

Clearing the cervical spine of significant injury in the obtunded victim of blunt trauma remains a controversial area. Cervical spine X-Rays are no longer used due to their poor quality (often the whole C-spine is not imaged) and sensitivity; the rate of missed injuries using X-rays may be as high as 20 percent (9). Computed tomography (CT) 
scan of the cervical spine is thus considered the most appropriate investigation to exclude cervical spine injury after blunt trauma in neurologically-free obtunded patients (10).

Although CT readily demonstrates fractures and malalignment, it provides limited direct evaluation of ligamentous and soft tissue injury, leading some to advocate the use of magnetic resonance imaging (MRI) to clear the spine and remove cervical collars in obtunded patients (11).

Schoenfeld and colleagues cautioned in 2010 against reliance on CT imaging alone to "clear the cervical spine" after blunt trauma, due to concerns over significant missed injuries (12). They advocated for an MRI in evaluating patients who are obtunded, or unexaminable, despite a negative CT scan. However, MRI has inherent risks to intubated victims of trauma. One of the key tenets of traumatic brain injury management is to prevents rises in the intracranial pressure (ICP) (3). An MRI of the cervical spine is performed in the supine position, for an extended period (up to 45 minutes). This is an undesirable length of time for all but the most stable patients to lie flat as the physiological consequences of reduced venous drainage of the injured brain could in theory be devastating.

A meta-analysis by Panczykowski et al in 2011 (32) attempted to definitively answer the question but was limited by significant flaws in data quality (33).

Over time, the evidence has evolved further in terms of robustness of evidence; in 2014, Vanguri et al (13) in a retrospective study showed that CT scan of the c-spine is an excellent tool to rule out c-spine injury with no further imaging necessary.

Two seminal articles published in 2016 and 2017 strongly supported the use of CT scan alone to exclude significant cervical spine injury in emergency department (ED) patients who failed NEXUS criteria; a prospective group of over 1600 alcohol-intoxicated patients, and a retrospective study of over 10000 patients $(14,15)$.

In 2018, Ajai Malhorta reported that MRI has limited utility after negative cervical CT in blunt trauma, as significant unstable injury missed on CT was infrequent (16). Once again, these were ED patients.

A natural extension of this work follows. If we can use a negative CT neck to exclude important cervical spine injury in the ED, can we rely on a negative CT to exclude cervical spine injury in patients who are intubated and ventilated?

Our study hypothesis is that the advance of CT over the last 20 years from 64 to 256 multi-slices (resulting in more precise images) has resulted in increased sensitivity of CT cervical spine in clearing the cervical spine in obtunded trauma patients, including those who are intubated and ventilated. Accordingly, removal of cervical collars is safe after CT clearance.

\section{Methods}

We conducted a retrospective analysis of all intubated trauma patients admitted to our Trauma Intensive Care Unit (TICU) during the period 1 August 2016 to 30 November 2018. Patients were identified from the Qatar national trauma registry. The study was approved by the Medical Research Committee (MRC), and informed consent requirements were waived by the Institutional Review Board (IRB).

We reviewed the rate of missed cervical injuries in patients who had their cervical collars removed based on a normal computed tomography (CT) scan of the cervical spine, as well as rates of collar-related complications. 
The primary outcome was evidence of missed cervical injury on initial computed tomography scan of the cervical spine. As our gold standard, we used clinical evidence of neurological weakness consistent with cervical spinal cord injury at time of hospital discharge.

All intubated adult trauma patients (age 14 and above) who had a cervical collar in situ, with a normal admission cervical spine CT who survived to hospital discharge, were included in the study (Table 1). Children, deceased patients, and those with positive findings on initial CT were excluded. 
Table 1

Demographic information and Results

\begin{tabular}{|c|c|}
\hline Age & $32.8 \pm 12.4$ \\
\hline Gender & $330(94.3)$ \\
\hline - Male & $20(5.7)$ \\
\hline \multicolumn{2}{|l|}{ - Female } \\
\hline Mechanism of injury & $235(67.1)$ \\
\hline - Road traffic accidents & $72(20.5)$ \\
\hline - Fall & $31(8.8)$ \\
\hline - Assault & $13(3.6)$ \\
\hline \multicolumn{2}{|l|}{ - Other } \\
\hline Traumatic Brain Injury & $180(51.6)$ \\
\hline Median GCS & 8 IQR (3-13) \\
\hline - at time of collar application & 10 IQR $(6-14)$ \\
\hline - at time of collar removal & $15 \operatorname{IQR}(12-15)$ \\
\hline \multicolumn{2}{|l|}{ - at time of transfer from ICU } \\
\hline Median ISS & 22 IQR (16-30) \\
\hline Collar placement & $329(94.0)$ \\
\hline - Pre-hospital & $21(6.0)$ \\
\hline \multicolumn{2}{|l|}{ - In-hospital } \\
\hline Computed Tomography (CT) test for neck & $350(99.7)$ \\
\hline - Number of patients tested & 0 \\
\hline \multicolumn{2}{|l|}{ - Positive findings } \\
\hline Magnetic Resonance Imaging tests & $30(8.5)$ \\
\hline - Number of patients tested & 0 \\
\hline \multicolumn{2}{|l|}{ - Positive findings } \\
\hline Median length of days with collar on & 2 IQR $(1-4)$ \\
\hline Specialty of doctors who made decision on collar removal & 22 \\
\hline • Neurosurgery & 328 \\
\hline - Trauma Intensive Care & \\
\hline
\end{tabular}




\begin{tabular}{|ll|}
\hline Age & $32.8 \pm 12.4$ \\
\hline Seniority of doctor who made decision on collar removal & $76(21.8)$ \\
- Senior consultant & $45(12.9)$ \\
- Spensultant & $218(62.6)$ \\
- Resident & $9(2.6)$ \\
\hline Number of patients intubated at time of collar removal & \\
\hline Patients with complications & $244(69.5)$ \\
\hline New neurology consistent with spinal cord injury at time of discharge & $7(2.0)$ \\
\hline Length of ICU stay & 10 IQR (4-18) \\
\hline Length of hospital stay & 25 IQR (13-44) \\
\hline
\end{tabular}

We interrogated the electronic patient records for information regarding the following: timing and place of application (prehospital or in hospital) and removal of the CC, duration of CC application and decision-maker for removal in terms of specialty and seniority, imaging findings (CT), length of stay in TICU and hospital, duration of intubation, and cervical collar complications such as acquired device-related pressure necrosis.

The GCS was correlated at time of application and removal of CC using the electronic patient record; the GCS recorded in the clinical notes immediately prior to the documented removal of the collar was noted. Evidence of cervical spine injury on Cervical CT was sought based on consultant radiologist reporting. Evidence of motor and sensory dysfunction was sought from the clinical notes related to time of admission, time of CC removal, and time of hospital discharge. When available, this information was also sought in terms of final patient disposition. Where available, MRI findings were used to correlate with clinical and cervical CT findings. Data was compared between the traumatic brain injury (TBI) and non-TBI groups.

\section{Statistical analysis}

data were presented as mean (standard deviation), proportion and median (range) whenever applicable. Correlation coefficient for relation between length of collar placement and length of hospital or ICU length of stay. The discriminatory power and predictive value of using cervical CT in patients without neurological deficit was performed. All data analyses were carried out using the Statistical Package for the Social Sciences, version 18 (SPSS, Inc., Chicago, IL).

\section{Results}

A total of 730 intubated trauma patients were identified during the study period. We excluded 380 patients (35 pediatric patients, 82 patients with suspected cervical spine fracture discovered by cervical CT, 71 patients had no Ccollar applied, 21 patients had no cervical CT, 136 patients died at the same admission, 35 patients had no C-collar data on their medical records). See Fig. 1.

Three hundred and fifty (350) patients met the inclusion criteria of having no cervical spine fracture on CT scan upon admission, age above 14 years, leaving the hospital alive, and C-collar applied by EMS or in the hospital. All 
were intubated trauma patients on the trauma intensive care unit and had their cervical collars removed based on the normally reported CT scan of the cervical spine. Results are depicted in Table 1.

Of the 350 patients who had their cervical collars removed on the Trauma Intensive Care Unit (TICU), $94 \%$ were male, and $6 \%$ female. The average age was 33 years. Seventy percent of patients were cleared of C-spine injury while still sedated and intubated.

The median injury severity score (ISS) was 22 , with a median ISS of 19 for the non-TBI group and 27 for the TBI group.

One hundred and 80 patients (51.5\%) had a co-existing traumatic brain injury (TBI). The mean GCS for the TBI group at collar removal was 9 , with an improvement to 13 by time of TICU discharge (Table 2).

Table 2

TBI vs non-TBI

\begin{tabular}{|c|c|c|c|}
\hline & Non-TBI $(n=170,48.4)$ & $\begin{array}{l}\text { TBI } \\
(N=181,51.6)\end{array}$ & P-value \\
\hline Age & $33.5 \pm 13.2$ & $32.2 \pm 11.6$ & 0.34 \\
\hline Gender & $160(94.1)$ & $171(94.5)$ & 0.89 \\
\hline - Males & $10(5.9)$ & $10(5.5)$ & \\
\hline \multicolumn{4}{|l|}{ - Females } \\
\hline Median GCS & 11 IQR (3-15) & 6 IQR (3-9) & 0.001 \\
\hline - at time of collar application & 11 IQR (7-15) & 9 IQR (5-12) & 0.001 \\
\hline - at time of collar removal & 15 IQR (14-15) & 14 IQR (10-15) & 0.001 \\
\hline \multicolumn{4}{|l|}{ - at time of transfer from ICU } \\
\hline ISS & 19 IQR (10-27) & 27 IQR $(21-33)$ & 0.001 \\
\hline Median length of days with collar on & $1 \mathrm{IQR}(1-2)$ & 2 IQR (1-5) & 0.001 \\
\hline Complications & $1(0.6)$ & $6(3.3)$ & 0.07 \\
\hline Length of ICU stay & 7 IQR (3-15) & 13 IQR (6-20) & 0.001 \\
\hline Length of hospital stay & 21 IQR (11-44) & 27 IQR (15-44) & 0.33 \\
\hline
\end{tabular}

The mean GCS at the time of cervical collar removal was 9, with a significant improvement of 4 points in GCS (mean 13) seen in most patients by the time of discharge from the TICU.

The average duration of collar application was 48 hours, with a range of less than one day to 31 days. The average duration of collar placement was significantly longer for traumatic brain injury (TBI) patients when compared with the non-TBI group.

There was no correlation between length of collar placement and length of hospital or ICU length of stay $(R=0.078)$. 
The mean length of TICU stay was $13.1 \pm 12.6$; median 10 (1-109), with a mean hospital length of stay of $35.1 \pm$ 36.3; median 25 (1-240).

The incidence of complications was inferred by the presence of submental or occipital pressure areas acquired or worsened on TICU. The rate of pressure area complications was $2 \%(n=7)$. The incidence of complications was too low to discern a correlation between length of collar placement and presence of pressure areas. It is noteworthy though, that the mean length of collar placement was 2 days and 9 hrs. (versus 2 days for those without complications). The length of hospital and TICU stays were also longer for those who suffered complications (mean hospital length of stay $55.9 \pm 62.9$ days; Median 50 (6-190), mean TICU length of stay $24.7 \pm 20.9$; Median 16 $(4-55))$.

Of note, all collars were removed in these seven patients with no new onset of neurological deficit. Most complications occurred in the TBI group.

The incidence of new neurological deficit as noticed at time of $I C U$ discharge was zero, and the incidence of new neurological deficit at time of hospital discharge was also zero.

We calculated the negative predictive value (NPV) of a normal CT neck for excluding significant cervical spine injury (Table 3). Based on the rate of positive and negative CT scans in terms of radiological cervical injury and using the clinical presence or absence of any form of quadriplegia or quadriparesis as the gold-standard for true cervical spine injury, the NPV was $100 \%$.

Table 3

Negative predictive value of normal cervical CT

\begin{tabular}{|lll|}
\hline & $\begin{array}{l}\text { Cervical fracture related } \\
\text { neurological deficit }\end{array}$ & $\begin{array}{l}\text { No neurological deficit related to } \\
\text { cervical fracture }\end{array}$ \\
\hline $\begin{array}{l}\text { CT positive showing cervical } \\
\text { fracture }\end{array}$ & 14 & 67 \\
$\begin{array}{l}\text { CT negative showing normal } \\
\text { cervical spine }\end{array}$ & 0 & 350 \\
\hline
\end{tabular}

Most collar removal decisions were made by the trauma team as opposed to the neurosurgical team. The seniority of the decision-maker was an attending consultant in $34 \%$ of decisions made, whereas Specialist/Hospitalists made the decision independently on $62 \%$ of occasions. A resident was the decision-maker in $3 \%$ of cases.

One patient was initially cleared of C-spine bony injury by a radiologist, but re-review by a neurosurgeon identified a bony injury. This was found to be a significant ligamentous injury on subsequent MRI. However, this was managed conservatively.

A second patient was found to have significant fracture of the occipital condyle. A subsequent MRI confirmed significant ligamentous injury in the absence of bony disruption. The collar was not removed in this patient.

\section{Discussion}

The results of our study reveal that using a negative CT scan of the spine in intubated victims of trauma to clear a cervical spine is a safe strategy. Cervical collars can therefore be removed in intubated trauma patients based on a 
normal CT scan of the cervical spine, as well as patients with impaired levels of consciousness who are not intubated.

Other studies have investigated the utility of CT scan to allow clearance of the C-spine in obtunded non-intubated patients presenting to the Emergency Department $(14,15)$. To the best of our knowledge this is the first study in the literature to focus on the feasibility of CT scan-based cervical spine clearance in intubated trauma victims admitted to a Trauma Intensive Care Unit.

This adds strength to the work of both Bush and Martin, published in 2016 and 2017 respectively. The studies reviewed cervical spine investigation and management in drug or alcohol-intoxicated patients.

In a prospective single-center observational study, Bush reported results on 1600 patients with blunt trauma, including 632 intoxicated patients. A clinically significant injury was defined as any injury that required or benefited from cervical spine immobilization or alternatively was at risk of any adverse effect because of the removal of spine precautions. Four patients were found to have central cord syndrome, and one patient had a missed ligamentous injury which was managed conservatively. None of these patients were at increased risk due to collar removal. They estimated a negative predictive value (NPV) of $99.2 \%$ for all injuries and $99.8 \%$ for unstable injuries, using a normal CT scan of the cervical spine (15).

The Western Trauma Association prospectively studied a cohort of over 10000 intoxicated blunt trauma patients across 17 sites; the negative predictive value of a normal CT cervical spine for significant missed injury was $100 \%$ (14). Martin and colleagues concluded that it was safe to remove a cervical collar in intoxicated patients with blunt trauma, based on a normal CT cervical spine.

It is useful to hypothesize as to why there was a shift in confidence in normal CT scans of the neck over the past decade. In 2012, Kaiser et al concluded from a retrospective review of 114 patients that 'CS MRI continues play a vital role in the workup of neurologically altered patients' (17). It is possible that the advent of multi-slice computed tomography scanners has enabled more accurate assessment of potential injury (18). During the period of our study, the CT-scan technology employed by our institution was 128-slice scanners; we now use 256-technology, which may improve our confidence even further.

It is further true that reporting errors will happen. Allesandrino and colleagues reported a very low (56 out of 59000) but significant incidence of missed cervical spine injuries on initial reporting by radiologists between 2004 and 2017. Some of these injuries may have a clinical significance (19). However, what is not clear is either the rate of missed diagnosis over time related to changes in CT multi slice row technology. What is even more difficult to ascertain is the effect of volume of reporting, and clinical case load of positive injuries, on quality of reporting.

Badhiwala et al performed a meta-analysis in 2015. Of note, they focused on the quality of both the CT scanning technology, as well as the quality of reporting. High-quality CT scans are defined as those protocolled with narrow slice width (1 to $3 \mathrm{~mm}$ ) and reconstruction in multiple planes. A well-interpreted CT study is defined as an image read by a health professional with special training and expertise in reading such images (that is, a consultant radiologist) rather than an on-call physician or radiology resident. Their conclusion was simple - with good technology and good interpretation, a normal CT cervical spine is all one needs (20). The presence of isolated transverse or spinous process fractures are not considered significant (21).

The practice in our institution is for all images to be reviewed by a consultant/attending radiologist, as well as a second doctor experienced at cervical spine CT review (usually a neurosurgeon). 
Our study also makes it clear that the specialty and seniority of decision-maker is irrelevant; whether a resident or consultant takes the decision to remove the collar does not result in increased risk to the patient. This is with the proviso that the negative CC CT has been reported by a consultant/attending radiologist.

The complication rate of pressure ulcers in our study was low, but not insignificant. Cervical collar use is commonly associated with pressure ulcers and associated with length of collar use (22). In our study, we were unable to identify a clear correlation between length of collar placement and development of pressure ulcers. We did, however find that complication rates were significantly higher in the TBI cohort. This may reflect the fact that collars were generally left on for longer in the TBI group. The latter may be explained by greater physician suspicion of cervical spine injury in TBI patients.

Pressure ulcers developed unnecessarily in seven patients in our study, who all eventually had their collars removed based on a normal CT scan of the neck. It is clear from work in elderly patients, that having a cervical collar in place for greater than 24 hours increases the complication rate (23).

In an interesting scoping review of seven studies addressing the question of how to prevent pressure areas in this subset of patients, two themes emerged. Firstly, a rate of zero was achievable with appropriate interventions. Second, discontinuing the collar/clearing the cervical spine should form part of any pressure ulcer prevention strategy in patients with cervical collars (24).

\section{Limitations}

It could be argued that our sample size is too small to make meaningful interpretations. However, taken together with the work of Martin and Bush, we believe that it is safe to remove a cervical collar in intubated trauma victims with normal cervical spine CT.

Some have argued that a normal CT scan needs to be paired with objective absence of motor deficit (i.e., moving lower limbs) (25). However, considering possible exacerbations of ICP, it is not viable to wait for signs of lower limb movement in patients with severe TBI requiring sedation, intubation and ventilation.

Not all units will have access to a) high quality multi-slice CT scanning technology, or b) a system of two experienced reviewers looking at CT scans of the cervical spine. This may limit the applicability of our findings to other settings.

The retrospective nature of our study made it difficult to investigate the incidence of all relevant complications of cervical collars. We could not, for example, ascertain the contribution of collars on ICP in our TBI patients.

Raised ICP and pressure ulcers are not the only complications of cervical collars. Although this was not evident during the 2-year period of our study, there is evidence that cervical collar placement itself may worsen injury, particularly in patients with ankylosing spondylitis (26). The collar itself may obscure significant soft tissue injury.

Another area of hitherto unexplored complication is the degree to which cervical collars contribute to agitation and confusion. Moran et al reported an association between semi-rigid cervical collar use and delirium in a small sample of 16 elderly patients (27). Although ICP rise is associated with collar use, it may be related to anxiety/agitation, rather than a direct compressive effect of the collar (28). This is an area of potential future research. 
Finally, clinical concerns persist; the consequences of a missed true cervical injury could be catastrophic for patients; this is of course why controversy rages. Therefore, the practice of not clearing the cervical spine after a normal CT cervical spine remains widespread (29).

However, Ertel has calculated the cost to society in terms a missed cervical spine injury on CT leading to neurological disability. Regardless of level of risk, the economic evaluation favored removal of the cervical collar and reducing its' complications, in all cases (30).

Veiga and Mitchell remind us that, although MRI may detect a significant number of ligamentous injuries, 'such injuries are rarely of clinical significance because they

rarely alter clinical management' (31).

To aid decision-making in terms of cervical collar removal in intubated victims of blunt trauma, we suggest a potentially useful algorithm (Fig. 2). This algorithm remains to be prospectively validated; however, we believe that sequentially following the steps included will allow safe removal of the cervical collar in this vulnerable patient population.

\section{Conclusion}

Cervical collars may be removed as early as possible if a well-performed, well-reported CT scan of the cervical spine is normal, regardless of the level of consciousness or intubation status of the patient.

We believe that it is time to stop the practice of deferring CT spine clearance in the presence of a normal cervical spine $\mathrm{CT}$ in unconscious victims of trauma.

Further prospective multi-center studies are needed to confirm these findings.

\section{Abbreviations}

CT SCAN: computerized tomography.

c-spine: cervical spine

TICU: Trauma intensive care unite

GCS: Glasgow Coma Scale

ICU: intensive care unit

CC: cervical collar

MRI: Magnetic resonance imaging

ICP: intra-cranial pressure

NEXUS: National Emergency X-Radiography Utilization Study.

EMS: emergency medical services 


\section{Declarations}

Ethics approval and consent to participate

The study was approved by the Medical Research Committee (MRC) of Hamad Medical Corporation (MRC-01-18452), and informed consent requirements were waived by the Institutional Review Board (IRB) at Hamad Medical Corporation, Doha, State of Qatar.)

Methods

All methods were carried out in accordance with relevant national/institutional/international guidelines and regulations. These conform to the editorial and publishing policies of the Nature Research journals.

Consent for publication

Not applicable

Availability of data and materials

All data generated or analysed during this study are included in this published article [and its supplementary information files]

Detailed datasets analysed during the current study available from the corresponding author on reasonable request Competing interests

The authors declare that they have no competing interests

Funding

No funding received

Authors' contributions

AH was responsible for conception, task distribution, data acquisition analysis from the EPR regarding cervical collar removal decisions and complications, and interpretation, image production and manuscript writing. GS made substantial contribution to conception, data analysis and interpretation and manuscript writing. AF, NA and BY contributed with acquisition and analysis of data. AM was responsible for methods implementation and statistical analysis. SR and HAT contributed to conception and design. AEM substantially revised the work.

All authors read and approved the final manuscript.

Acknowledgements

Not applicable 


\section{References}

1. United States Patent Office. http://patft.uspto.gov/netacgi/nph-Parser?

Sect1=PT01\&Sect2=HITOFF\&p=1\&u=/netahtml/PTO/srchnum.html\&r=1\&f=G\&l=50\&d=PALL\&s1=2389690.PN.

Page accessed 17 May 2020

2. Sundstrøm T, Asbjørnsen H, Habiba S, Sunde GA, Wester K. Prehospital use of cervical collars in trauma patients: a critical review. J Neurotrauma. 2014;31(6):531-540. doi:10.1089/neu.2013.3094

3. American College of Surgeons. 2018. Advanced trauma life support: student course manual. $10^{\text {th }}$ Edition.

4. Lockey DJ, Coats T, Parr MJ. Aspiration in severe trauma: a prospective study. Anaesthesia. 1999;54(11):10978.

5. Goutcher CM, Lochhead V. Reduction in mouth opening with semi-rigid cervical collars. Br J Anaesth. 2005;95(3):344-8.

6. Stone MB, Tubridy CM, Curran R. The effect of rigid cervical collars on internal jugular vein dimensions. Acad Emerg Med. 2010;17(1):100-2.

7. Black JM, Cuddigan JE, Walko MA, Didier LA, Lander MJ, Kelpe MR. Medical device related pressure ulcers in hospitalized patients. Int Wound J. 2010 Oct;7(5):358-65. doi: 10.1111/j.1742-481X.2010.00699.x. PMID: 20561094.

8. Stiell IG, Clement CM, McKnight RD, Brison R, Schull MJ, Rowe BH, Worthington JR, Eisenhauer MA, Cass D, Greenberg G, MacPhail I, Dreyer J, Lee JS, Bandiera G, Reardon M, Holroyd B, Lesiuk H, Wells GA. The Canadian C-spine rule versus the NEXUS low-risk criteria in patients with trauma. N Engl J Med. $2003 \mathrm{Dec}$ 25;349(26):2510-8.

9. Fisher A, Young WF. Is the lateral cervical spine x-ray obsolete during the initial evaluation of patients with acute trauma? Surg Neurol. 2008 Jul;70(1):53-7; discussion 58. doi: 10.1016/j.surneu.2007.08.011. Epub 2008 Jan 18. PMID: 18207543.

10. Baekgaard JS, Christensen RE, Lee JM, Eid Al, Eskesen TG, Steinmetz J, Rasmussen LS, King DR, Velmahos GC. Cervical Spine Clearance in Trauma Patients with an Unreliable Physical Examination. World J Surg. 2020 Apr;44(4):1113-1120. doi: 10.1007/s00268-019-05307-1. PMID: 31802188.

11. Liao S, Jung MK, Hörnig L, Grützner PA, Kreinest M. Injuries of the upper cervical spine-how can instability be identified? Int Orthop. 2020 Jul;44(7):1239-1253. doi: 10.1007/s00264-020-04593-y. Epub 2020 May 25. PMID: 32451654

12. Schoenfeld AJ, Bono CM, McGuire KJ, Warholic N, Harris MB. Computed tomography alone versus computed tomography and magnetic resonance imaging in the identification of occult injuries to the cervical spine: a meta-analysis. J Trauma. 2010 Jan;68(1):109-13.

13. Vanguri P, Young AJ, Weber WF, Katzen J, Han J, Wolfe LG, Duane TM. Computed tomographic scan: it's not just about the fracture. J Trauma Acute Care Surg. 2014 Oct;77(4):604-7

14. Martin, Matthew J. ; Bush, Lisa D. ; Inaba, Kenji; et. al. The WTA C-Spine Study Group Cervical spine evaluation and clearance in the intoxicated patient, Journal of Trauma and Acute Care Surgery. December 2017 - Volume 83 - Issue 6 - p 1032-1040.doi: 10.1097/TA.0000000000001650

15. Bush L, Brookshire R, Roche B, et al. Evaluation of Cervical Spine Clearance by Computed Tomographic Scan Alone in Intoxicated Patients with Blunt Trauma. JAMA Surg. 2016;151(9):807-813.

doi:10.1001/jamasurg.2016.1248

Page $13 / 16$ 
16. Malhotra A, Durand D, Wu X, et al. Utility of MRI for cervical spine clearance in blunt trauma patients after a negative CT. European Radiology. 2018 Jul;28(7):2823-2829. DOI: 10.1007/s00330-017-5285-y.

17. Kaiser ML, Whealon, Barrios C, Kong , Lekawa ME, Dolich . The current role of magnetic resonance imaging for diagnosing cervical spine injury in blunt trauma patients with negative computed tomography scan. Am Surg. 2012;78(10):1156-1160

18. Brown C, Foulkrod K, Reifsnyder A, Bui E, Lopez I, Hummell M, Coopwood B. Computed Tomography versus Magnetic Resonance Imaging for Evaluation of the Cervical Spine: How Many Slices Do You Need?. The American surgeon. 2010. 76. 365-8.

19. Alessandrino, F., Bono, C.M., Potter, C.A. et al. Spectrum of diagnostic errors in cervical spine trauma imaging and their clinical significance. Emerg Radiol 26, 409-416 (2019). https://doi.org/10.1007/s10140-019-01685-0

20. Badhiwala JH, Lai CK, Alhazzani W, et al. Cervical spine clearance in obtunded patients after blunt traumatic injury: a systematic review. Ann Intern Med. 2015;162(6):429-437. doi:10.7326/M14-2351

21. Duane TM, Young AJ, Vanguri P, Wolfe LG, Katzen J, Han J, Mayglothling J, Whelan J, Aboutanos MB, Ivatury R, Malhotra A. Defining the cervical spine clearance algorithm: A single-institution prospective study of more than 9,000 patients. J Trauma Acute Care Surg. 2016 Sep;81(3):541-7. doi: 0.1097/TA.0000000000001151.

22. Jackson D, Sarki AM, Betteridge R, Brooke J. Medical device-related pressure ulcers: A systematic review and meta-analysis. Int J Nurs Stud. 2019;92:109-120. doi:10.1016/j.ijnurstu.2019.02.006

23. Nakanishi T, Mitra B, Ackland H, O'Reilly G, Cameron P. Time in Collars and Collar-Related Complications in Older Patients. World Neurosurg. 2019 Sep;129:e478-e484. doi: 10.1016/j.wneu.2019.05.187. Epub2019 May 29.

24. Lacey L; Palokas M; Walker J. Preventative interventions, protocols or guidelines for trauma patients at risk of cervical collar-related pressure ulcers, JBI Database of Systematic Reviews and Implementation Reports: December 2019 - Volume 17 - Issue 12 - p 2452-2475,doi: 10.11124/JBISRIR-2017-003872

25. Como J, Leukhardt W, et al. Computed Tomography Alone May Clear the Cervical Spine in Obtunded Blunt Trauma Patients: A Prospective Evaluation of a Revised Protocol. The Journal of trauma. 2011. 70. 345-9; discussion 349. 10.1097/TA.0b013e3182095b3c.

26. Clarke A, James S, Ahuja S. Ankylosing spondylitis: inadvertent application of a rigid collar after cervical fracture, leading to neurological complications and death. Acta Orthop Belg. 2010;76(3):413-415.

27. Moran C, Kipen E, Chan P, et al. Understanding post-hospital morbidity associated with immobilisation of cervical spine fractures in older people using geriatric medicine assessment techniques: A pilot study. Injury. 2013;44(12):1838-1842. doi:10.1016/j.injury.2013.04.009

28. Sparke A, Voss S, Benger J. The measurement of tissue interface pressures and changes in jugular venous parameters associated with cervical immobilisation devices: a systematic review. Scand J Trauma Resusc Emerg Med. 2013;21:81. Published 2013 Dec 3. doi:10.1186/1757-7241-21-81

29. Chilvers G, Porter K, Choudhary S. Cervical spine clearance in adults following blunt trauma: a national survey across major trauma centres in England. Clin Radiol. 2018 Apr;73(4):410.e1-410.e8. doi:

10.1016/j.crad.2017.11.006. Epub 2017 Dec 8.

30. Ertel AE, Robinson BR, Eckman MH. Cost-effectiveness of cervical spine clearance interventions with litigation and long-term-care implications in obtunded adult patients following blunt injury. J Trauma Acute Care Surg. 2016 Nov;81(5):897-904. 
31. Veiga JRS, Mitchell K. Cervical spine clearance in the adult obtunded blunt trauma patient: A systematic review. Intensive Crit Care Nurs. 2019 Apr;51:57-63. doi: 10.1016/j.iccn.2018.11.001. Epub 2018 Dec 1.

32. Panczykowski DM, Tomycz ND, Okonkwo DO. Comparative effectiveness of using computed tomography alone to exclude cervical spine injuries in obtunded or intubated patients: meta-analysis of 14,327 patients with blunt trauma. J Neurosurg. 2011 Sep;115(3):541-9. doi: 10.3171/2011.4.JNS101672. Epub 2011 May 27. PMID: 21619408.

33. Traynelis VC, Kasliwal MK. Cervical clearance. J Neurosurg. 2011 Sep;115(3):536-9; discussion 539-40. doi: 10.3171/2011.2.JNS102121. Epub 2011 May 27. PMID: 21619406.

\section{Figures}

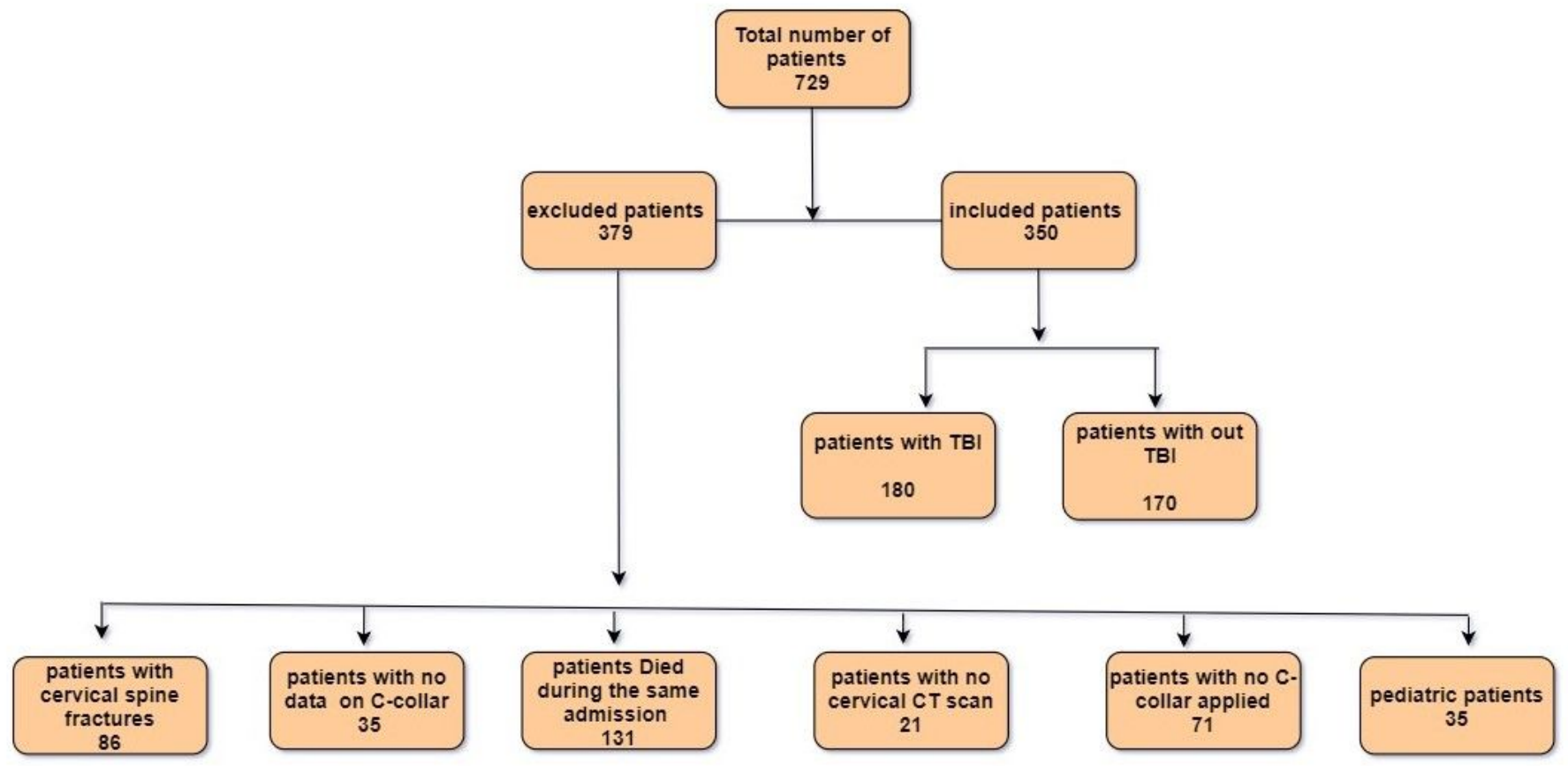

Figure 1

Subject inclusion 


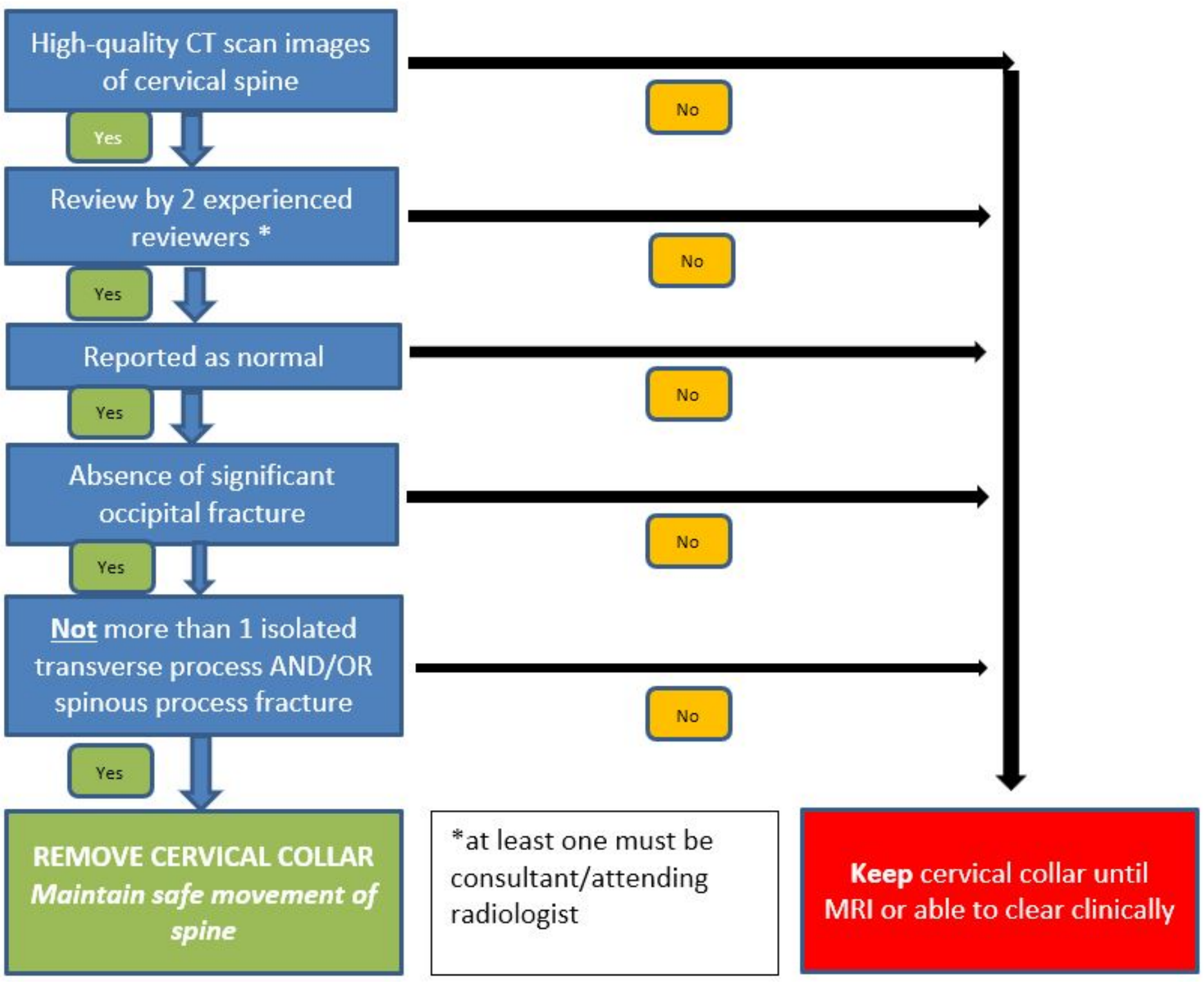

Figure 2

Pathway Cervical Collar Removal 